\title{
O PROJETO “OPENFAB": METODOLOGIA DE PROJETO APLICADA AOS ALUNOS INGRESSANTES DO CURSO DE ENGENHARIA INTEGRANDO ADMINISTRAÇÃO, DESIGN E ENGENHARIA
}

Patricia Antonio de Menezes Freitas - pantonio@maua.br Instituto Mauá de Tecnologia - Escola de Engenharia Mauá Praça Mauá, 01 - 09580-900 - São Caetano do Sul - SP

Angelo Eduardo Battistini Marques - angelo.marques@maua.br

Keiti Pereira Vidal de Souza -e-mail: keiti.vidal@maua.br

Claudia Alquezar Facca-e-mail:claudiafacca@maua.br

Hector Alexandre Chaves Gil-e-mail: hector.gil@maua.br

Resumo: Este artigo tem como objetivo mostrar a aplicação, os resultados e também a percepção dos alunos de primeiro ano dos cursos de Engenharia com respeito à ação de aprendizagem baseada em projeto (PjBL) na disciplina Fundamentos de Engenharia, denominada OpenFab. Na concepção da matriz curricular do primeiro ano dos cursos de Engenharia do Instituto Mauá de Tecnologia a disciplina Fundamentos de Engenharia desempenha o papel de eixo integrador entre as disciplinas, buscando colocar em prática os conhecimentos abordados nas disciplinas básicas. Para o desenvolvimento do Projeto OpenFab utilizou-se a metodologia do Design Thinking.

Palavras-chave: Aprendizagem por Projetos, Design Thinking, PBL, PjBL.

\section{INTRODUÇÃO}

As novas Diretrizes Curriculares Nacionais (DCNs) para os cursos de Engenharia, aprovadas em 2019 (MEC/CNE/CES, 2019) apontam explicitamente a importância do uso de metodologias ativas e, em particular na abordagem de projetos (PBL ou PjBL), como forma de promover competências transversais.

Assim, ganham destaque as metodologias tal como o ensino baseado em projetos, ou Project Based Learning (PBL), com lastro no desenvolvimento de competências, na aprendizagem colaborativa e na interdisciplinaridade (MEC/CNE/CES, 2019).

Em consonância com essas recomendações, nos projetos pedagógicos dos cursos do Instituto Mauá de Tecnologia (IMT) esse papel é desenvolvido pela disciplina Fundamentos de Engenharia, que vem sendo aprimorada há vários anos (FACCA et al., 2019; FREITAS et al., 2018), e está situada como um dos eixos do curso - o Profissional e Formativo de Habilidades Específicas. O segundo eixo, Motivacional e de Habilidades Transversais, é trabalhado pela 


\section{Evento On-line}

prática de Projetos e Atividades Especiais (PAE) e Tutoria. Dessa forma, a disciplina de Fundamentos de Engenharia assume um papel central na formação inicial dos alunos à medida em que dialoga com todas as disciplinas da formação básica, buscando trazer sentido e significado às aprendizagens.

Figura 1. Estrutura do 1o ano dos cursos de Engenharia EEM-IMT

\section{1a SÉRIE - Engenharia}

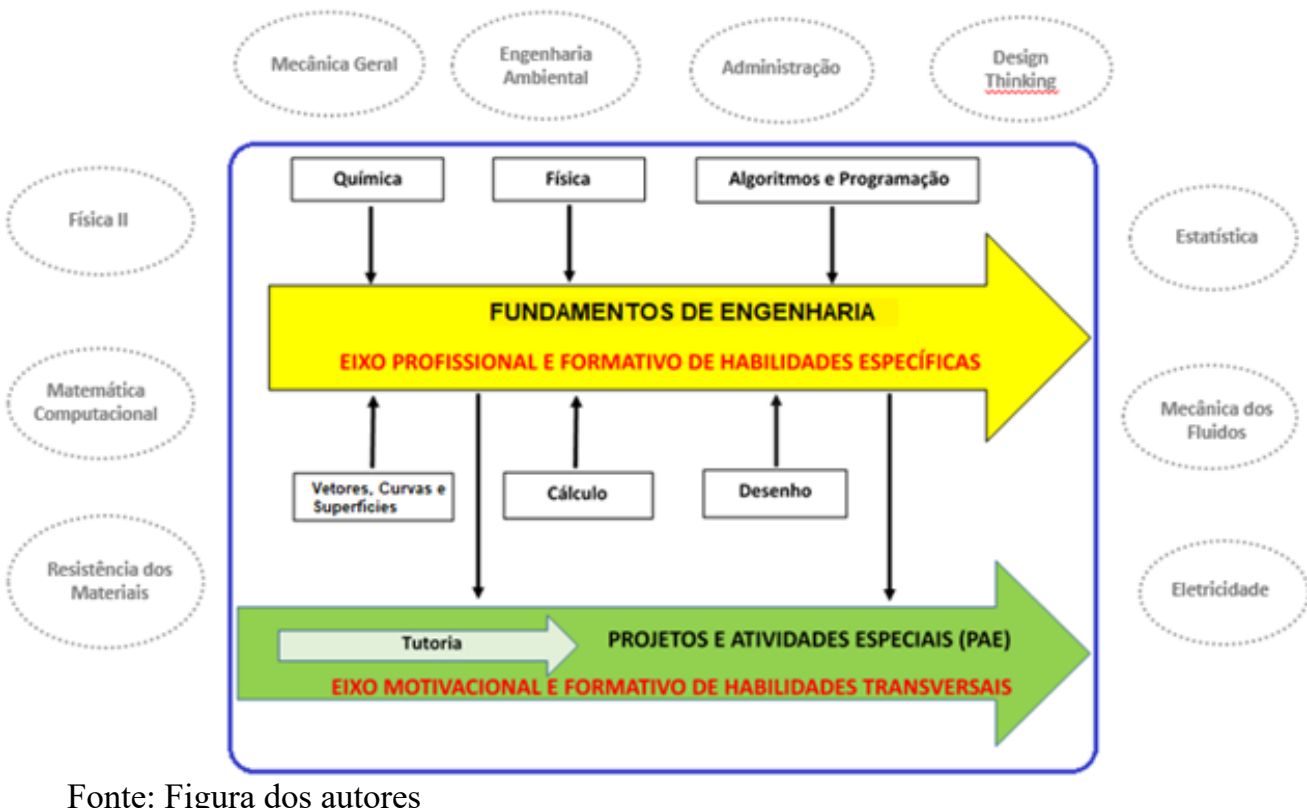

A disciplina é estruturada em aulas "Teóricas ou Aulas de Grupo" com aproximadamente 60 estudantes e aulas "Práticas ou Aulas de Turma", com 30 alunos. Nas aulas de "Grupo" são desenvolvidos os conceitos fundamentais, buscando sempre que possível o uso de metodologias ativas com exercícios resolvidos de forma cooperativa e dinâmica, como por instrução por pares (MAZUR, 2013) e Jigsaw (ARONSON \& PATNOE, 2011).

Nas aulas de "Turma" são desenvolvidas atividades de cunho prático, como atividades em sala de aula, utilizando softwares, tais como Microsoft Excel, PowerPoint, Geogebra, Word, entre outros, além de ensaios em laboratórios específicos (de mecânica, elétrica, química, etc) que, além de propiciar uma vivência ligada à cada curso de Engenharia oferecido pela instituição, permitem que o estudante aplique conceitos de medidas e incertezas com o uso de diversos instrumentos, conversão de unidades, análise dimensional, confecção de gráficos e aplicações de modelos matemáticos a partir de dados reais obtidos nesses laboratórios. Nessas turmas também é desenvolvida a atividade de projeto, denominada de "OpenFab", cujo objetivo é desenvolver um produto/serviço inovador aplicando a metodologia do Design Thinking, integrando as áreas de Administração, Design e Engenharia, além de considerar os impactos socioambientais envolvidos. Essa integração das três áreas e a orientação aos estudantes acontece sob diferentes formas: a) em sala de aula com o Professor da disciplina; b) Com a equipe docente da disciplina (as áreas de formação acadêmica dos Professores praticamente completam as áreas da Engenharia) em atendimento; c) Docentes de áreas específicas são 
convidados a orientar os estudantes ao longo do Projeto; d) A interface com os monitores e corpo Técnico traz uma aproximação e o apoio dos Coordenadores de Curso.

O Design Thinking, como metodologia de projetos, foi criado na década de 1970 a partir de uma observação e sistematização das formas como engenheiros, designers e outros profissionais desenvolvem seus processos criativos na concepção de novos produtos (VIANNA et al., 2012). É uma abordagem que tem como valores a empatia, a colaboração e a experimentação. Por ser focado no usuário, o Design Thinking tem na Empatia com o usuário sua principal marca. Os projetos, portanto, são concebidos a partir de necessidades reais de algum grupo ou de uma população; o que as pessoas precisam ou desejam é o ponto de partida para posteriormente pensar no produto ou serviço. Portanto há aqui uma mudança de foco, primeiro na demanda e depois na oferta que levam a possíveis caminhos e soluções inovadoras para futuros negócios. O Design Thinking procura valorizar técnicas como brainstorming (tempestade cerebral) com pessoas de diferentes áreas para "pensar fora da caixa", incentivando a criatividade colaborativa (FACCA, 2020).

De acordo com Vianna et al., 2012, o projeto foi desenvolvido passando pelas seguintes fases baseadas na metodologia do Design Thinking:

a. Imersão: o processo criativo começa pela compreensão do problema no contexto e na visão do usuário, na busca da compreensão do que o "incomoda". A imersão pode criar a "fagulha" que irá inspirar o processo de ideação.

b. Análise e síntese são processos alternativos de abordagem de um problema. A análise consiste em separar os problemas em partes menores, observadas individualmente. Na síntese, o problema é observado como um todo. Aqui, a empatia dos desenvolvedores com os usuários é crucial no sentido de compreender as necessidades e perceber as raízes do problema.

c. Ideação é a fase que inclui o brainstorming na qual se procuram gerar muitas ideias mas, que irão, aos poucos, desembocar nas soluções centrais que serão trabalhadas no projeto.

d. Prototipação é a construção de modelos experimentais a serem testados pelos usuários para validar a ideia e fazer ajustes necessários. Às vezes, são feitos vários protótipos que, ao longo do tempo e dos testes, vão evoluindo até se chegar ao "produto final".

e. Implementação é a fase final de colocar em uso o produto desenvolvido. Nessa fase, esperase que a maior parte dos problemas tenham sido sanados, mas sempre ajustes são necessários e evoluções podem ser pensadas em trabalhos futuros.

\section{O PROJETO "OPENFAB"}

O desenvolvimento dos trabalhos começou no início do segundo semestre do curso. Os alunos foram divididos em equipes de no máximo seis integrantes. Cada equipe criou a sua empresa fictícia, com nome, identidade visual, missão, visão e valores. Os cargos de gestão foram escolhidos pelos estudantes, pelos quais responderam durante o semestre, sendo cada aluno diretor de uma área específica. Os cargos foram Diretor Executivo, de Marketing, de Projeto, Produto, Logística e Financeiro. Em seguida, os alunos receberam um cronograma de tarefas a serem executadas e começaram a definir o escopo do seu trabalho. A orientação é feita pelos professores da disciplina durante as aulas de "Turma" e também com atividades de capacitação que acontecem ao longo do ano, como oficinas sobre cada uma das etapas do Design Thinking, como falar em público e precificação de produtos. 


\subsection{Fase I - Imersão}

Após as orientações sobre as técnicas de imersão, cada grupo deve escolher as técnicas a serem utilizadas e planejar a sua imersão, que deve ser entregue ao professor. A partir daí o grupo tem duas semanas para realizar e entregar os resultados dessa etapa. Todas essas entregas parciais, ao mesmo tempo que direcionam o cronograma dos alunos, servem como avaliação formativa, com comentários do professor direcionados a cada equipe.

\subsection{Fase II - Análise}

Tendo entregue os resultados da imersão, os grupos passam a analisar os resultados obtidos pelas pesquisas realizadas com vistas à ideação. As possibilidades e restrições apontadas pelos possíveis usuários são listadas para que o grupo parta para a fase de definição do seu produto.

\subsection{Fase III - Ideação}

$\mathrm{Na}$ fase de ideação, as possibilidades são colocadas e analisadas pelo grupo e as ideias começam a convergir e direcionar ao produto final. Muitos grupos chegam a esta fase com uma ideia bem clara do que irão fazer. Mesmo assim, a ideação, tendo como perspectiva a análise feita a partir da imersão direta com o público alvo, serve como medida para a aceitação e aperfeiçoamento da ideia. Ao final desta fase, o grupo apresenta um seminário rápido ( 5 minutos) para a turma, sendo observado pelo professor, servindo, novamente, como avaliação formativa, que vai orientar a apresentação final. Como são alunos ingressantes, muitos deles sem experiência em fazer apresentações, é fornecido um roteiro para a montagem da apresentação. Esse roteiro inclui a apresentação da empresa, das funções de cada membro do grupo, os objetivos do projeto, a técnica e os resultados da imersão, as análises e resultados da ideação e um desenho do produto final.

\subsection{Fase IV - Prototipação}

Uma vez apresentadas as ideias, os grupos passam a executá-las. O IMT possui uma infraestrutura de laboratórios, FabLab Mauá, com computadores e pessoal técnico (que inclui monitores da disciplina especificamente designados para essa tarefa) como apoio aos alunos. Nesta etapa, os alunos participam de oficinas de como calcular o preço de um produto, que deve ser apresentado no final.

\subsection{Fase V - Implantação e conclusão dos projetos}

Terminado o protótipo, os alunos apresentam seus produtos em duas etapas. A primeira é para uma banca de professores convidados, que avaliam a partir de um check list com quesitos como o respeito ao tempo pré estabelecido (sete minutos), a abordagem das etapas do Design Thinking, a clareza da apresentação, a qualidade das ideias apresentadas e a postura do grupo. Além de somativa, essa avaliação pode ser considerada também formativa, porque os professores questionam e sugerem mudanças no projeto ou mesmo na metodologia de trabalho. 


\section{COBENCE 2020

\section{"Os desafios para formar hoje o engenheiro do amanhă"}

Figura 2: Apresentação final para a banca de professores
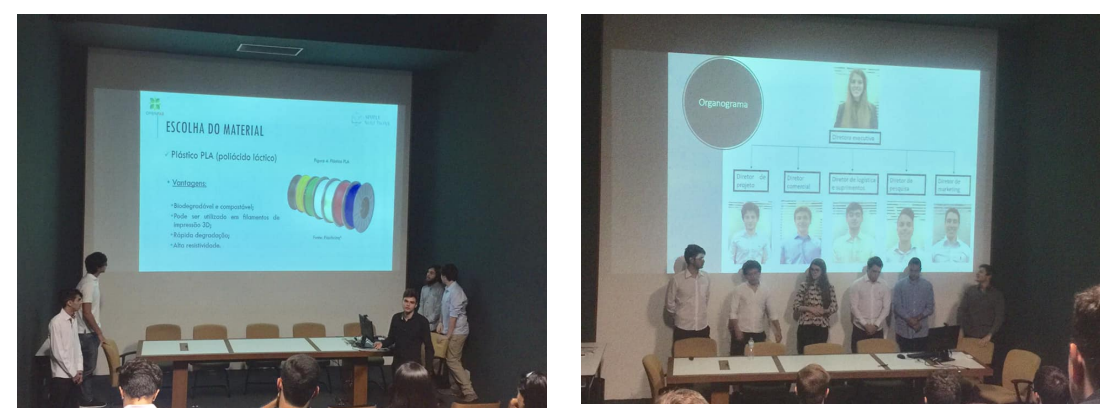

Fonte: Fotos dos autores

$\mathrm{Na}$ sequência, os alunos apresentam e demonstram seus produtos na "Exposição Jovem Empreendedor", aberta à comunidade e também avaliada pelos professores da Instituição e professores convidados de outras instituições de ensino de graduação em engenharia.

Figura 3: Exposição Jovem Empreendedor
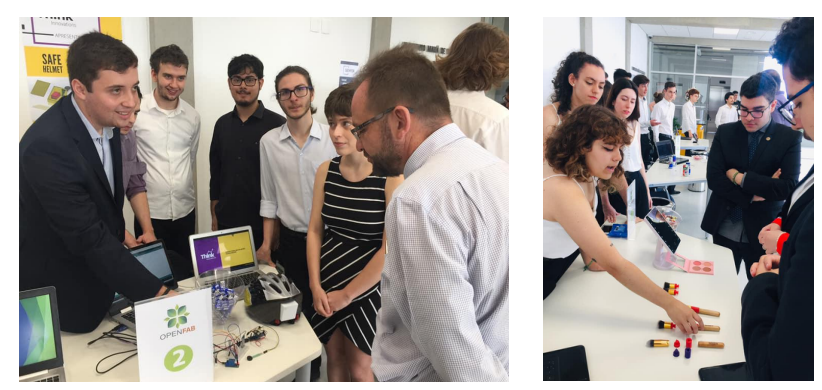

Fonte: Fotos dos autores

\section{RESULTADOS}

Para avaliar a percepção dos alunos foi elaborado um questionário online dirigido, respondido por 372 dos cerca de 450 alunos que concluíram o projeto OpenFab.

\subsection{Percepção quanto à importância do projeto na formação profissional}

Inicialmente, os alunos foram questionados se o projeto teve alguma contribuição efetiva na sua formação como profissional de Engenharia, sendo que $69 \%$ dos alunos entenderam que sim e $21 \%$ entenderam que foi uma contribuição parcial e $10 \%$ entendem que não contribuiu. Esse resultado é extremamente positivo, pois mostra que a maioria dos alunos entendeu a importância da atividade proposta. 
Figura 4: Percepção dos alunos quanto à contribuição do OpenFab na Formação profissional

O projeto OpenFab contribuiu para sua formação como Engenheiro(a)?

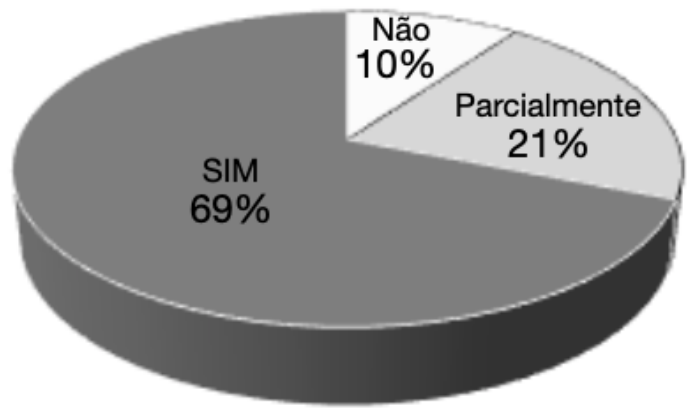

Fonte: Figura dos autores

\subsection{Percepção quanto à integração com outros cursos}

Um dos objetivos do projeto é a integração entre as áreas de Engenharia, Administração e Design. Na percepção dos alunos, semelhante ao resultado anterior, $68 \%$ percebem claramente essa integração entre as diversas áreas, somados aos $20 \%$ que consideram essa integração parcial, temos que $88 \%$ dos alunos percebem a interdisciplinaridade presente no projeto.

Figura 5: Percepção dos alunos quanto à integração do OpenFab com outras áreas de conhecimento

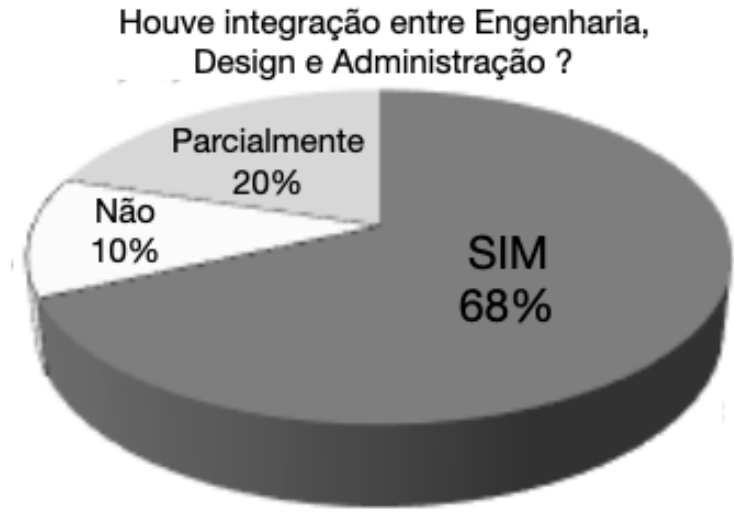

Fonte: Figura dos autores

\subsection{Contribuição das demais disciplinas}

Outra proposta importante dentro da disciplina é a integração com as demais disciplinas do primeiro ano do curso. Para aferir essa percepção, questionamos os alunos com relação a quais disciplinas mais contribuíram no desenvolvimento do projeto. A disciplina de Desenho foi apontada por quase $90 \%$ dos alunos. Essa percepção dos alunos é bem condizente com o desenvolvimento do projeto, pois a grande maioria dos grupos fabricaram seus protótipos no FabLab, usando a impressora $3 \mathrm{D}$ ou a cortadora laser, equipamentos para os quais a prototipação digital deve ser bem elaborada. Observou-se também que, as disciplinas Cálculo e Física também trouxeram importantes contribuições ao projeto. 


\section{Evento On-line}

Figura 6: Disciplinas do primeiro ano que trouxeram conhecimentos utilizados no projeto Quais disciplinas trouxeram conhecimentos que você utilizou no OpenFab?

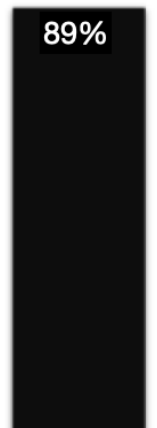

Desenho

Fonte: Figura dos autores

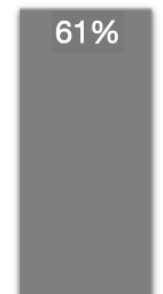

Cálculo

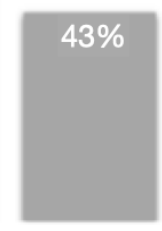

Física

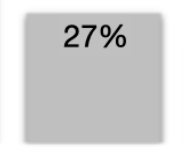

Fundam. Eng

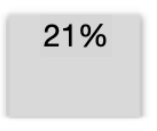

Química

\section{$18 \%$}

Algoritmos Vetores e GA

\subsection{Percepção quanto às competências desenvolvidas}

Baseados nas competências transversais para os cursos de Engenharia apontadas nas DCNs de 2019 (CNE/CES, 2019), apresentamos aos alunos uma série de competências para que apontassem, na sua visão, qual (ou quais) foram as mais desenvolvidas na atividade do projeto. As mais significativas, na visão dos alunos, foram "Projetar e conduzir experimentos" (67\%), "Autonomia" (62\%), "Comunicar-se de diversas formas" (57\%), "Desenvolver e utilizar novas ferramentas" (54\%). Essa percepção é muito importante, à medida em que mostra aqueles aspectos mais significativos na visão dos alunos, o fato de desenvolver a capacidade de projetar e a autonomia, dois fatores muito enfatizados durante as aulas de orientação de projeto. A comunicação, que também foi enfatizada, seja na apresentação intermediária, seja nos comentários dos professores na apresentação final.

Figura 7: Percepção dos alunos quanto às competências desenvolvidas

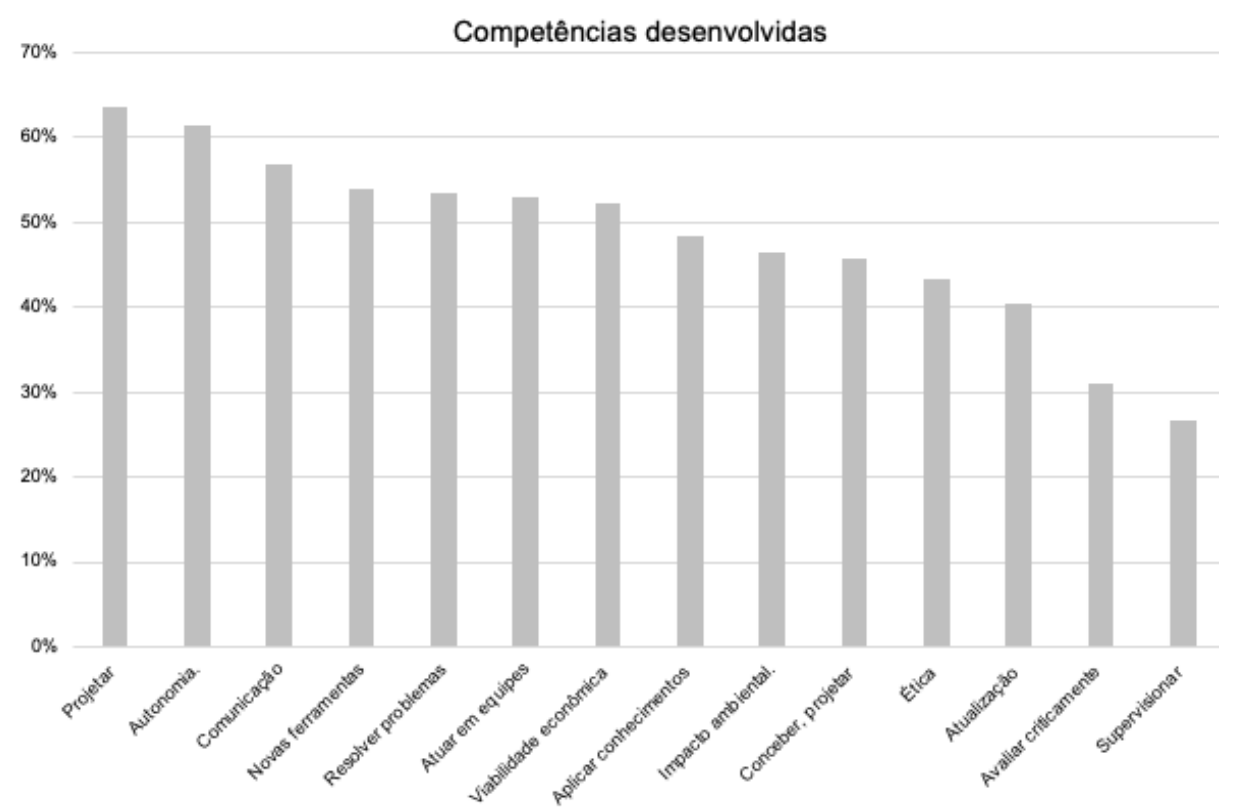

Fonte: Figura dos autores 


\section{CONCLUSÕES}

Observando as respostas obtidas podemos inferir que, de uma maneira geral, os alunos têm uma boa compreensão dos objetivos do trabalho e o avaliam de forma positiva. As percepções sobre a contribuição do projeto na sua formação profissional, a interdisciplinaridade (interação com outras áreas de conhecimento) e o uso dos conhecimentos das demais disciplinas do primeiro ano do curso são relevantes porque mostram a importância percebida pelos alunos quanto ao projeto e, consequentemente, com relação à própria disciplina, estando de acordo com aquilo que é estabelecido como objetivo no projeto pedagógico dos cursos.

Alguns ajustes ainda são necessários, como por exemplo a orientação quanto à gestão do tempo, principal dificuldade dos alunos, o que poderá ser feito no próximo ano.

\section{REFERÊNCIAS}

ARONSON, Elliot.; PATNOE, Shelley. Cooperation in the Classroom: The Jigsaw Method. (3rd ed.). Ed. Pinter \& Martin Ltd., 2011.

FACCA, Claudia Alquezar A Contribuição do Pensamento do Design na Formação do Engenheiro: O Espaço do Fab Lab como Experiência Transversal. Tese de Doutorado. PPG Design. Universidade Anhembi Morumbi. São Paulo, 2020.

FACCA, C. A.; FREITAS, P. A. D. M.; GIL, H. A. C.; GUZZO, F. P.; BARBOSA, A. M. O Design Thinking como Metodologia de Projeto Aplicada ao Ensino de Engenharia: O Projeto "Open Fab" na Disciplina de Introdução à Engenharia. In: Anais do COBENGE 2019 - XLVII Congresso Brasileiro de Educação em Engenharia. Fortaleza: ABENGE - Associação Brasileira de Educação em Engenharia, 2019.

FREITAS, Patrícia A. de M. et al. Introdução à Engenharia como disciplina estruturante do primeiro ano de um curso de Engenharia. In: Brazilian Applied Science Review. V. 2, N. 3, p. 1015-1027. Curitiba, jul/set 2018. ISSN 2595-3621. Disponível em $<$ http://www.brjd.com.br/index.php/BASR/article/view/473/409>. Acesso em 18 de dezembro de 2018.

MEC, CNE, CES. Resolução CNE/CES no 2, de 24 de abril de 2019. Diretrizes Curriculares Nacionais do Curso de Graduação em Engenharia, 2019.

MAZUR, Eric. Peer Instruction: A user's Manual. (3rd Ed); Pearson Education, 2013.

VIANNA, Maurício et al. Design Thinking: inovação em negócios. $2^{\mathrm{a}}$ ed. Rio de Janeiro, RJ: MJV Press, 2013. 161 p. 


\title{
THE “OPENFAB” PROJECT: A PROJECT METHODOLOGY APPLIED TO FRESHMEN ENGINEERING STUDENTS INTEGRATING DESIGN, BUSINESS AND ENGINEERING
}

\begin{abstract}
This paper aims to show the application, results and also the Engineering first-year students perception with respect to the Project-Based Learning action (PBL or PjBL) in the Fundamentals of Engineering discipline, called OpenFab. In the conception of the curricular matrix of the first year of Engineering courses at the Instituto Maua de Tecnologia, the discipline Fundamentals of Engineering plays the role of integrating axis between the disciplines, seeking to put into practice the knowledge covered in the basic disciplines. For the development of the OpenFab Project, the Design Thinking methodology was used.
\end{abstract}

Keywords: Design Thinking, Engineering Education, PBL, PjBL, Project-Based Learning, 